\title{
Summary Report of NIST/MSC Workshop on Traceability in Length
}

\author{
Dennis A. Swyt \\ Chief \\ Precision Engineering Division \\ U.S. DEPARTMENT OF COMMERCE \\ Technology Administration \\ National Institute of Standards \\ and Technology \\ Gaithersburg, MD 20899-0001
}

QC

100 



\title{
Summary Report of NIST/MSC Workshop on Traceability in Length
}

\author{
Dennis A. Swyt \\ Chief \\ Precision Engineering Division \\ U.S. DEPARTMENT OF COMMERCE \\ Technology Administration \\ National Institute of Standards \\ and Technology \\ Gaithersburg, MD 20899-0001
}

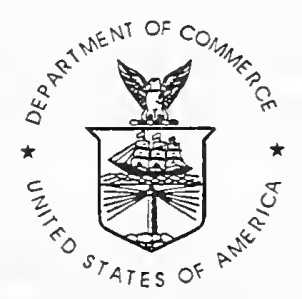

U.S. DEPARTMENT OF COMMERCE William M. Daley, Secretary

TECHNOLOGY ADMINISTRATION

Gary R. Bachula, Acting Under Secretary for Technology

NATIONAL INSTITUTE OF STANDARDS

AND TECHNOLOGY

Raymond G. Kammer, Director 



\title{
Summary Report of NIST/MSC Workshop on Traceability in Length
}

\author{
Dennis A. Swyt \\ Chief, Precision Engineering Division \\ National Institute of Standards and Technology
}

Keywords: Dimensional Measurement, Length, Traceability, Measurement Uncertainty

Abstract: The National Institute of Standards and Technology (NIST) conducted a workshop on Feb. 4, 1998 on U.S. industry needs in the area of traceability in length measurements. The workshop focused on issues which U.S. manufacturing companies, particularly smaller ones, may have in meeting their need to demonstrate traceability of their dimensional measurements to the international and national standard of length. The workshop was attended by nineteen persons representing a cross-section of organizations of the type with strong institutional interests in the issue; ten were from various organizations in the private sector and nine from various units of NIST. The conclusion of the workshop was that there is a need for education, training, and dissemination of information about the new requirement in traceability for statements of uncertainty. In addition, there is a role for NIST in facilitating, leading, or providing an element of the education, training, or dissemination of information regarding traceability and measurement uncertainty associated with that need.

\section{Introduction}

This report summarizes the results of a Feb. 4, 1998 National Institute of Standards and Technology workshop, held in conjunction with the 1998 annual meeting of the Measurement Science Conference [1], on issues which U.S. manufacturing companies, particularly smaller ones, may have in meeting their need to demonstrate traceability of their dimensional measurements to the international and national standard of length.

Pervasiveness of Dimensional Measurements in Manufacturing Measurements made by U.S. industry on the dimensions of features of the products which they manufacture, such as the size of parts for assembly, the roundness of engine bores, and the linewidths of semiconductor microelectronic circuit elements, are considered to be one of the most pervasive types of physical measurement in all of industry. In order to achieve accuracy and uniformity in dimensional measurements within and among manufacturing companies within and among different countries, dimensional measurements can be made traceable, that is, referenced to national standards of length and through them to the international standard of length, the meter.

NIST/PED Mission Role Within the United States, it is the mission of the Precision Engineering Division of the National Institute of Standards and Technology to support U.S. industry by providing practical access to the national and international standard of length through a program of measurement research and services. 
NAS Panel Issue A panel of the National Academy of Sciences (NAS), which reviews the technical programs of NIST, has recommended that PED examine the mechanisms by which American companies currently establish the traceability of length measurements and whether they might have issues and problems in doing so that NIST might contribute to resolving. The workshop reported here is a result of that recommendation.

\section{Announcement of Workshop}

Announcement of the workshop to potential attendees was made in three ways. An announcement of meeting was published in the January bulletin of the National Conference of Standards Laboratories. A prospectus for the workshop was sent electronically or by conventional mail to attendees of previous NIST workshops on dimensional metrology. The prospectus was also sent to individual representatives of various industry and NIST associated with provision or use of accreditation and measurement services in the dimensional area (Appendix A).

\section{Attendees of the Workshop}

The workshop was attended by nineteen persons, approximately half from U.S. industry and half from various units of NIST. The attendees represented a cross-section of organizations that have strong institutional interests in the issue of traceability of dimensional measurements made by U.S. manufacturing companies (Attendance list given in Appendix B).

The institutions represented carry out: aircraft-aerospace manufacturing (Boeing North America, Boeing Aerospace), automotive manufacturing (Cummins Engine), electronics system manufacturing (Litton Guidance and Controls), dimensional-measurement instrument manufacturing (Federal Products), commercial dimensional calibration laboratory accreditation services (A2LA), central-government dimensional calibration laboratory accreditation services (National Voluntary Laboratory Accreditation Program (NVLAP) ), dimensional-measurement inspector certification and quality system assessment (American Society of Quality), private dimensional-measurement consulting (Dimensional Measurement, Measurement Associates, Tumax Engineering), commercial dimensional calibration services (Accu-Check), and centralgovernment dimensional calibration services (NIST Calibration Program, NIST Office of Standard Reference Services, and NIST Precision Engineering Division).

\section{Background Information Provided in the Workshop as Context}

Scenario Behind Issue Raised to NIST by its NAS Assessment Panel Small-to-medium-size U.S. companies manufacture dimensioned parts for sale to customers. The companies measure the dimensions of the parts to show that the parts conform to customer specifications. To assure that those measurements are trustworthy, customers assess or audit the companies' "quality systems". The assessors or auditors require that such companies demonstrate that their dimensional measurements are "traceable". Smaller companies have difficulty dealing with the requirement to 
demonstrate "traceability". NIST might help somehow to overcome that difficulty.

Definitions of Traceability Different national and international standards-related organizations have at various times provided different definitions and interpretations of the concept of "traceability". Historically the principal definition of traceability which influenced U.S. manufacturing companies was that used by the U.S. Department of Defense. Subsequently, different, but interrelated, definitions of traceability have been given by: the International Standards Organization (ISO 9001, ISO 10012, ISO Guide 25, and International Vocabulary of Basic and General Terms in Metrology); the American National Standards Organization, the American Society of Quality, and the National Conference of Standards Laboratories (ANSI/ASQ 9001 and ANSI/NCSL Z540-1, counterparts to the ISO documents); and NORAMET (the North American Cooperation in Metrology). The definitions, interpretations, and interrelations of these various definitions of traceability as presented in the workshop are provided in Appendix C. As indicated in the workshop, except through its National Voluntary Laboratory Program which requires traceability for its accreditation of calibration laboratories, NIST does not define, set standards for, require, or enforce traceability.

Functional Definition of Traceability Used for the Workshop As reported in the workshop, the common elements of the various definitions seem to be converging toward a definition of traceability in dimensional measurements of manufactured parts which includes a number of key elements. Traceability is most basically a condition which a buyer of dimensioned parts requires of the manufacturer/seller of those parts to show conformity of part dimensions to buyer's specifications. That requirement is set either directly through a part specification or indirectly through a quality-management specification. In such traceability, the results and the uncertainties of the dimensional measurements which are made are to be referenced to the national and international standard of length. This referencing of measurements is to be through a welldocumented and unbroken chain of timely, task-specific comparisons, with measurement results and uncertainties shown for each comparison in the chain.

As indicated in the workshop, the functional definition of traceability used in the workshop includes the notion of "task-specific" traceability, a concept being introduced into draft international standards. Task-specific traceability means that, in effect, one must show traceability to an international/national standard of the specific measurement quantity in question. For example, for a measurement of "out of roundness", traceability need be shown to a "primary standard" of roundness, which is, in turn, traceable to the (linear) international standard unit of length, the meter; similarly gear and microelectronic-circuit linewidth need be traceable to the tops of traceability chains for gear form and microelectronic-circuit linewidth, respectively, with each top of a traceability chain then related, respectively, to the international standard unit of length.

\section{Discussion in the Workshop}

To address the main question of the workshop - Are U.S. companies, particularly smaller 
manufacturing companies, having any problem with meeting requirements for traceability in length, which NIST might help solve? - the participants in the workshop were asked to identify: (1) who in U.S. manufacturing industry needs traceability in dimensional measurements; (2) what are the old, new, and alternative sources they have for attaining that traceability; (3) what issues or problems they are having in attaining it; and (4) what possible actions NIST might take to help them in resolving those issues or solving those problems.

The following are capsule summaries of specific problem areas identified by individual attendees of the workshop in the course of group discussion of these questions.

Product Function and Traceability For top management of one company which manufactures products with dimensioned parts and which acts as a supplier, either internal or external, the real need is to: a) achieve form, fit, and function of those dimensioned parts. In order to so, the next need is to b) demonstrate the uncertainty of those measurements. In order to do, the next need is to: c) demonstrate traceability, which - from this company's point of view - is one component of uncertainty, rather than the other way around. In order to do so, the next need is for a quality system in the best sense, which defines a, b, and c, including "stickers" (that is, the certificates placed on instruments by an assessor to shown conformity to calibration requirements, including traceability).

Traceability of the Process of Measurement of Part Dimensions The functional performance of a product, such as the compression and the oil consumption of an engine, leads to specifications on the manufacturing process and on part tolerances. The real need is to validate that the measurement process is valid, not just that traceability is shown in some formal sense. The question is: are the measurements on the parts traceable (or are merely the standards traceable).

Auto Industry QS 9000 versus ISO 9000 Some in the auto industry have gotten a false sense of security because of the (International Organization for Standardization) ISO 9000 certification of suppliers. They find gages on production lines that do not function and auditors that don't always go deep enough. In part as result, the latest QS 9000 (the U.S. automobile manufacturing industry's quality standard analogous to ISO 9000), in addition to ISO 9000 requirements and classic quality tools, adds more laboratory accreditation requirements.

Problem Level in Companies' Dimensional Measurement Quality System While formal laboratory accreditation through NVLAP looks at the two highest levels of a company's overall dimensional measurements, that is, the overall quality management system and that for gage calibrations, the production-gage level, which actually measures the manufactured part, is not seen by that accreditation process and may be dysfunctional.

Only Want Sticker Supposedly representative of a situation in many companies needing to conform to the automobile industry QS 9000 specification is that in one company which needed to establish traceability for its 180 dial indicators. What that requirement entailed was understood in two ways, depending on the location within the company of the people involved. At the shop 
level, the requirement translated into a formal requirement for a sticker, the certificate placed on instruments by an assessor to shown conformity to calibration requirements, unconnected to the performance of the gage or the adequacy of the procedures for its use. As a result, the process of calibration of the dial gages and review of the method by which those gages were actually being used indicated that, while nominally "calibrated", a number of the gages and the procedures by which they were being used were faulty. Such situations indicate a need for increased education and training regarding calibration, measurement, and traceability at the shop level.

Qualification of Suppliers The basis for qualifying suppliers of one company represented at the workshop involves: master-prototype parts, which embody the functional-performance characteristics of importance; and the process, including measurement, for producing the parts. In order to satisfy the company's requirements as customers, both the master-prototype parts and the measurement portion of the manufacturing process which produces parts are being specified in terms of traceability.

Statements of Uncertainties in Production Measurements With uncertainty the key to traceability, another company is developing tools for use in manufacturing for the estimation of the actual uncertainties in production measurements. Also this company is educating its suppliers on: (1) the need for them to estimate the actual uncertainties in their production measurements; and (2) how to make statements of uncertainty.

Unsatisfied Wish to Outsource A large aircraft company, in which top-management wishes as a cost-economy measure to outsource its internal calibration service functions, finds that it is unable to do so because small-and-medium-size commercial calibration-service companies do not adequately understand the traceability and uncertainty requirements of ISO 10012 to provide an adequate service. As a result, the aircraft company is being required to do the calibrations internally. A possible solution is for NIST to somehow help small-and-medium-size enterprises (SMEs) get educated on ISO 10012 and the like.

Change in Available Skill Levels In large companies, the sophistication of in-process metrology is increasing, with use of uncertainties "leaking out" of calibration laboratories into shop processes. Because it is profitable to do so, more small-and-medium-sized companies are setting up metrology laboratories. Historically, the Department of Defense (DoD) was the source of people technically trained to deal with measurements. With less of them available from DoD backgrounds, the small-and-medium-sized companies are setting up their metrology laboratories with less-trained people. How does anyone help out these small companies?

Five-Person Shops The thousands of small manufacturing companies which act as suppliers of dimensioned parts, that is, the "five-person shops", such as those represented by the membership of the National Tooling and Machining Association (NTMA), have a problem with dealing with traceability in dimensional measurements in general and with dealing with uncertainty in dimensional measurements in particular. The biggest problem is with uncertainty. In contrast, in foreign countries, small shops deal effectively with measurement uncertainty. The basis for the 
problem for U.S. companies is education and culture. A solution for this issue is for NIST to "certify" uncertainties at all levels of the system.

Traceability of Hardness Measurements Since there are no NIST artifact standards for hardness testers, how is possible that there be commercial laboratories accredited to do hardness testing as they claim? Is the answer that they can have traceability without being traceable to NIST, that is traceability to (non-NIST) "national standards", including those of the American National Standards Institute (ANSI), the American Society of Testing and Materials (ASTM), and the Department of Defense (DoD), which somehow define a "consensus" standard?

Specific Issues from Engine Manufacturer Our company is looking to NIST for: (1) random, as well as currently provided periodic, surface finish artifact standards from NIST; and National Voluntary Laboratory Accreditation Program (NVLAP) and American Association of Labotatory Accreditation (A2LA) accreditation for form; surface finish; and coordinate measuring machines (CMMs). The Physikalisch-Technische Bundesanstalt (PTB) of Germany now offers Deutscher Kalibrierdienst (DKD) accreditation in all three areas; NIST/NVLAP does not. We have the PTB/DKD accreditation in CMMs already; in FY98 will obtain it for surface finish; and will for form in FY1999/2000.

\section{Resolving Discrepancies in Measurements to Different Countries' National Laboratories} Without a specific example in mind, is there a mechanism for resolving discrepancies between the measurement results of companies which are referenced to the national laboratories of different countries, such as PTB Germany and NIST U.S.?

A New Dimensional Metrology Network A new system should be implemented comprised of NIST providing practical realizations of international standards, satellite laboratories certifying artifacts that provide certification for measurement processes, certified laboratories certifying standard parts and gages, and users using the standard parts to certify production processes and parts, with NIST certifying uncertainty levels and procedures for all levels of the network.

\section{Results of Questionnaire}

In addition to the open discussion, individual attendees were offered the opportunity to complete an optional hand-in comment sheet to give their views of the workshop's basic questions after their participation in the group discussion. The questionnaire asked workshop attendees to complete the statements: (1) (Yes or No), there is a problem with U.S. manufacturing companies, particularly smaller ones, in satisfying requirements for traceability in length; (2) The most significant aspect of the problem as I see it is this ; (3) The part that NIST might play in helping solve this problem is this ; and (4) My other comments are . The attendees responses to the questionnaire are tabulated in Appendix D.

Is There a Problem? Fourteen of fifteen (93\%) of the attendees of the workshop who completed questionnaires responded: Yes, there is a problem with U.S. manufacturing companies, 
particularly smaller ones, in satisfying requirements for traceability in length.

The Most Significant Aspect? Ten of fifteen (67\%) of the respondents indicated that some aspect of education, training, or dissemination of information about the "new" requirements of traceability for statements of uncertainty, including how to generate an uncertainty budget, was the most significant aspect of the problem with U.S. manufacturing companies, particularly smaller ones, in satisfying requirements for traceability in length. The general problem is that there is a lack of understanding, and lack of standardized procedure, for applying the generic ISO Guide to Uncertainties in Measurement (GUM) to particular types of measurements and calibrations.

The Part NIST Might Play? Thirteen of fifteen (87\%) of the respondents indicated that there is some role for NIST to play in addressing the education, training, or dissemination of information aspect of the problem with U.S. manufacturing companies, particularly smaller ones, in satisfying requirements for traceability in length.

The specific actions that NIST might take to help solve the problem of U.S. manufacturing companies, particularly smaller ones, in satisfying requirements for traceability in length through education, training, and dissemination of information indicated by individual respondents were:

- Work with industry to identify educational needs and ways to help

- Take leadership role in encouraging education/training, not necessarily doing it

- Involve the NIST Manufacturing Extension Partnership Program (MEP)

- Look for collaborators/partners (MEP?) to put short courses together

- $\quad$ Alert education institutions that this is what is needed along with measurement training

- Education of industry to NIST's point of view via publications/ workshops

- Workshops, limited consulting, and partnerships

- Education for understanding of the active participation and effort needed on the part of metrology, inspection, and quality personnel

- $\quad$ Education, example, guidance

- Dissemination of current information

- $\quad$ Provide certification/validation of measurements at all levels

- $\quad$ Strategic plan for NIST in educating measurement-intensive companies

- Continue to offer uncertainty analysis in the training courses/workshops that are offered in measurement-discipline-specific courses such as the Dimensional Metrology Seminars done in conjunction with the Measurement Science Conference

- New initiative to fund this type of effort as a technical or technology transfer

- Support documentary standards efforts of NCSL/ASTM

- Follow up with a forum at the 1998 NCSL Conference 


\section{Follow-Up Actions}

Pre-Planned Follow-Up Actions Reported to Workshop Attendees The convener of the workshop reported to the attendees the intention to compile the summary results of this workshop, send copies of draft summary report to workshop attendees for comment, report the results/options to NAS Panel Mar. 4, 1998, and carry out the options chosen by NIST management.

Workshop Attendee-Group's Recommendations for Additional Follow-Up Actions Attendees of the workshop recommended that NIST also:

- $\quad$ Send the final report for distribution to a broad audience

- $\quad$ Send the report to the National Measurement Requirements Committee of the National Conference of Standards Laboratories

- Accept the invitations to submit the final report for publication in the newsletters of:

- The National Conference of Standards Laboratories; and

- The American Society of Quality Measurement Division

- $\quad$ Provide the report on the NIST website

- Include an option and mechanism for feedback on the workshop question in any distribution mechanism.

\section{Conclusion}

This report summarizes the results of a NIST workshop, held in conjunction with the Measurement Science Conference, on issues that U.S. manufacturing companies, particularly smaller ones, have in meeting their need to demonstrate traceability of their dimensional measurements to the international and national standard of length.

The workshop was attended by nineteen persons, approximately half from U.S. industry and half from various units of NIST, representing a cross-section of organizations of the type with strong institutional interests in the issue of traceability of dimensional measurements made by U.S. manufacturing companies.

There was a clear consensus arrived at in the workshop that:

- There is a problem with U.S. manufacturing companies, particularly smaller ones, in satisfying requirements for traceability in length;

- The most significant aspect of this problem is in the need for education, training, and dissemination of information about the "new" requirements of traceability for statements of uncertainty, including how to generate an uncertainty budget; and 
- There is a role for NIST in facilitating, leading, or providing an element of the education, training, or dissemination of information regarding traceability and measurement uncertainty associated with the problem with U.S. manufacturing companies, particularly smaller ones, in satisfying requirements for traceability in length.

\section{References}

1. Measurement Science Conference, Symposium and Workshop, Pasadena, California, Feb. 5-6, 1998. 
Appendix A. Prospectus for NIST Length Traceability Workshop

Dennis A. Swyt, NIST, 301-975-3463, dennis.swyt@nist.gov

Summary: This prospectus is for a half-day NIST workshop on Feb. 4, 1998 in Pasadena, CA to identify issues, opportunities, and possible actions by NIST regarding the means by which U.S. manufacturers, including small-and-medium size enterprises (SMEs), achieve traceability to the international and national standards of length which traceability they need to compete.

Time/Place: 1:00-5:00PM, Wed. Feb. 4, 1998, Hospitality Rm, Pasadena Center, Pasadena CA.

Background: Traditionally in the U.S., "traceability" was the ability of a company to demonstrate to the Department of Defense, to whom it was supplying manufactured goods under militarystandard specifications, that the measurements the supplier made to insure conformity of products to "mil-standards" were referenced to appropriate national standards. With the globalization of markets, however, and the greater imposition by customers of quality standards on suppliers, it has been asserted that an increasing number of U.S. manufacturers are being required to demonstrate the new form of traceability, the formal and explicit documentation of an unbroken chain of reference measurements to an international or national standard, including the uncertainty of the measurements at each link in the chain. It has also been suggested that U.S. manufacturers, particularly SMEs, are encountering problems, issues, and difficulties in defining and achieving traceability of their length measurements in order to satisfy the demands of their customers. A Board of Assessment of NIST Programs, which provides oversight to the Precision Engineering Division of NIST, which, in turn, is responsible for realization and dissemination in the U.S., of the international/national standard of length, has recommended that NIST/PED examine the situation with a view to providing some form of new aid to U.S. manufacturers, particularly SMEs, in meeting their new length-traceability needs.

Purpose: In the context of the background statement above, the purpose of the workshop is to provide an opportunity for those with a stake in the issue of length traceability in U.S. manufacturing to define industry needs, issues, and opportunities for suppliers of length measurements and standards used to establish length traceability.

Attendees: The workshop is open to representatives of U.S. manufacturers, measurement laboratories, standards bodies, accreditation groups, federal and state agencies, and others with a stake and interest in traceability of length measurements in the U.S. who see issues in the area and wish to contribute to their identification and potential resolution.

Format: The workshop is to be a half-day working meeting with participation by all attendees encouraged, following an agenda generally in the form of: Welcome; Statement of Purpose of Meeting and Background on Study; Self-Introductions by Attendees, Including Identification of Own Role in Traceability; Agree on Working Definition of Traceability, Length Traceability; Identify Key Reasons for Industry Needing Length Traceability; Identify Who in U.S. Industry Needs Length Traceability; Identify Old/New/Alternative Sources of Length Traceability; Identify Issues/Problems in Attaining Length Traceability; Suggestions of Participants on Follow-Up Actions; Summary/Conclusion; Adjourn. 
Appendix B. Attendees of Feb. 4, 1998 NIST/MSC Workshop on Traceability in Length

\begin{tabular}{|c|c|c|c|}
\hline Affiliation & Name & Address & Phone, FAX, E-mail \\
\hline Accu-Check & Robert Vaughan & $\begin{array}{l}8583 \text { Refugee Road } \\
\text { Pinckerton, OH } 43147\end{array}$ & $\begin{array}{l}\text { P: } 614-837-4243 \\
\text { F: } 614-837-4467\end{array}$ \\
\hline A2LA & Peter Unger & $\begin{array}{l}656 \text { Quince Orchard Rd } \\
\# 620 \\
\text { Gaithersburg, MD } 20899\end{array}$ & $\begin{array}{l}\text { P: } 301-670-1377 \\
\text { F: } 301-869-1495\end{array}$ \\
\hline $\begin{array}{l}\text { American Society } \\
\text { of Quality }\end{array}$ & DeWayne Sharp & $\begin{array}{l}\text { MQD/ASQ } \\
2590 \text { Malaga Drive } \\
\text { San Jose, CA } 95425\end{array}$ & $\begin{array}{l}\text { P: 408-264-1519 } \\
\text { F: 408-264-1519 } \\
\text { dbsharp@metrology.org }\end{array}$ \\
\hline $\begin{array}{l}\text { Boeing } \\
\text { North American }\end{array}$ & Curtis Ashford & $\begin{array}{l}\text { Boeing North American } \\
3370 \text { Miraloma Avenue } \\
\text { MS HC } 02 \\
\text { Anaheim, CA } 92803\end{array}$ & $\begin{array}{l}\text { P: 714-762-7850 } \\
\text { F: 714-762-2674 } \\
\text { curtis.m.ashford@boeing.com }\end{array}$ \\
\hline $\begin{array}{l}\text { Boeing } \\
\text { Space Systems }\end{array}$ & Dave Lorenzen & $\begin{array}{l}\text { Boeing Space Systems } \\
5301 \text { Bolsa Ave. } \\
\text { Huntington Beach, CA } \\
92647\end{array}$ & $\begin{array}{l}\text { P: } 714 \text { - 896-4574 } \\
\text { dave.lorenzen@boeing.com }\end{array}$ \\
\hline Cummings Engine & Steven Stahley & $\begin{array}{l}\text { Cummings Engine Company } \\
635 \text { S. Mapleton } \\
\text { Columbus, IN } 47201\end{array}$ & $\begin{array}{l}\text { P: } 812 \text { - 377-4802 } \\
\text { s.r.stahley@notesbridge.cummings } \\
\text {.com }\end{array}$ \\
\hline $\begin{array}{l}\text { Dimensional } \\
\text { Metrology }\end{array}$ & Ralph Veale & $\begin{array}{l}\text { Dimensional Metrology } \\
\text { Consulting Services } \\
629 \text { W. Lynfield Drive } \\
\text { Rockville, MD } 20850\end{array}$ & $\begin{array}{l}\text { P: 301-762-6197 } \\
\text { rcveale@aol.com }\end{array}$ \\
\hline Federal Products & Duane Christy & $\begin{array}{l}\text { Federal Products Company } \\
1144 \text { Eddy Street } \\
\text { Providence, RI } 02905\end{array}$ & $\begin{array}{l}\text { P: 401-784-3271 } \\
\text { F: 401-784-3344 } \\
\text { dchristy@fedprod.com }\end{array}$ \\
\hline Litton & Brian Conroy & $\begin{array}{l}\text { Litton Guidance \& Control } \\
19601 \text { Nordhoff Street } \\
\text { Northridge, CA } 91324\end{array}$ & $\begin{array}{l}\text { P: 818-717-6872 } \\
\text { F: 818-717-6881 } \\
\text { conroyb@littongcs.com }\end{array}$ \\
\hline $\begin{array}{l}\text { Measurements } \\
\text { Associates }\end{array}$ & W. G. Eicke & $\begin{array}{l}\text { Measurement Associates Inc. } \\
11113 \text { Whisperwood Lane } \\
\text { Rockville, MD 20852-3634 }\end{array}$ & $\begin{array}{l}\text { P: 301-530-1331 } \\
\text { F: 301-530-8950 } \\
\text { weick@us.net }\end{array}$ \\
\hline NIST/SRM & Robert Gettings & $\begin{array}{l}\text { NIST/SRM } \\
\text { Bldg. } 202 \text { Rm } 212 \\
\text { Gaithersburg, MD } 20899\end{array}$ & $\begin{array}{l}\text { P: 301-975-5573 } \\
\text { F: 301-926-4751 } \\
\text { robert.gettings@nist.gov }\end{array}$ \\
\hline $\begin{array}{l}\text { Tumax } \\
\text { Engineering }\end{array}$ & Ray McClure & $\begin{array}{l}\text { Tumax Engineering } \\
5721 \text { Crestmont Avenue } \\
\text { Livermore, CA } 94550\end{array}$ & $\begin{array}{l}\text { P: } 510-449-0932 \\
\text { F: 510-371-4631 } \\
\text { ermcclure@email.msn.com }\end{array}$ \\
\hline
\end{tabular}




\begin{tabular}{|l|l|l|l|}
\hline $\begin{array}{l}\text { NIST Calibration } \\
\text { Program }\end{array}$ & C. Brickenkamp & $\begin{array}{l}\text { NIST Calibration Program } \\
\text { Room 236, Bldg. 820 } \\
\text { Gaithersburg, MD 20899 }\end{array}$ & $\begin{array}{l}\text { P: 301-975-4291 } \\
\text { cbrickenkamp@nist.gov }\end{array}$ \\
\hline $\begin{array}{l}\text { NIST Calibration } \\
\text { Program }\end{array}$ & Ernest Garner & $\begin{array}{l}\text { NIST Calibration Program } \\
\text { Rm 237 Bldg 820 } \\
\text { Gaithersburg, MD 20899 }\end{array}$ & $\begin{array}{l}\text { P: 301-975-2007 } \\
\text { ernestgarner@nist.gov }\end{array}$ \\
\hline NIST/NVLAP & Doug Faison & $\begin{array}{l}\text { NIST/NVLAP } \\
\text { NN 282 } \\
\text { Gaithersburg, MD 20899 }\end{array}$ & $\begin{array}{l}\text { P: 301-975-5304 } \\
\text { faisond@nist.gov }\end{array}$ \\
\hline NIST/NVLAP & Steve Doty & $\begin{array}{l}\text { NIST/NVLAP } \\
\text { NN282 }\end{array}$ & $\begin{array}{l}\text { P: 301-975-4857 } \\
\text { F: 301-926-2884 }\end{array}$ \\
& & Gaithersburg, MD 20899 & stephen.doty@nist.gov \\
\hline NIST/PED & Ted Doiron & $\begin{array}{l}\text { NIST/PED } \\
\text { Bldg. 220 B-113 } \\
\text { Gaithersburg, MD 20899 }\end{array}$ & $\begin{array}{l}\text { P: 301-975-3472 } \\
\text { F: 301-869-0822 } \\
\text { doiron@nist.gov }\end{array}$ \\
\hline NIST/PED & Howard Harary & $\begin{array}{l}\text { NIST/PED } \\
\text { Bldg 220 B-113 } \\
\text { Gaithersburg, MD 20899 }\end{array}$ & $\begin{array}{l}\text { P: 301-975-3485 } \\
\text { howard.harary@nist.gov }\end{array}$ \\
\hline NIST/PED & Dennis Swyt & NIST/PED & Bldg. 220 A109 \\
& Gaithersburg, MD 20899 & $\begin{array}{l}\text { F: 301-975-3463 } \\
\text { dennis.swyt@nist.gov }\end{array}$ \\
\hline
\end{tabular}


Appendix C. Definitions of Traceability in Measurements

In the workshop presentation, seven different documentary standards or specifications were reported as providing some form of definitions of traceability, many of these definitions being interrelated.

ISO VIM Definition of Traceability The International Organization for Standardization's International Vocabulary of Basic and General Terms in Metrology (VIM) defines traceability as:

The property of the result of a measurement or the value of a standard whereby it can be related to stated references, usually national or international standards, through an unbroken chain of comparisons all having stated uncertainties [C1].

DoD Mil Std 45662A The U.S. Department of Defense's Military Standard 45662A on Calibration System Requirements, in use from 1988 until canceled by DoD in 1995, defines traceability as:

The ability to relate individual measurement results through an unbroken chain of calibrations to U.S. national standards maintained by the U.S. NBS (National Bureau of Standards, now the National Institute of Standards and Technology), physical constants with values assigned/accepted by NBS, national standards of other countries correlated with U.S. standards, ratio type calibrations or comparison to consensus standards. Measurement, test, and inspection equipment and standards shall be calibrated using measurement standards whose calibration is traceable [C2].

In its January, 1995 Notice of Cancellation of Mil-Std-45662A, DoD stated that:

Further acquisitions should refer to: ISO 10012-1, Quality Assuring Requirements for Measuring Equipment; American National Standards Institute (ANSI) / National Conference of Standards Laboratories (NCSL) Z540-1, General Requirements for Calibrations Laboratories and Measuring and Test Equipment; or comparable standards as alternatives to MIL-STD-45662A [C3].

ISO 9001 and ANSI Q9001 The International Organization for Standardization's ISO 9001 on Quality Systems and the word-for-word equivalent American National Standard Institute and American Society of Quality Control ANSI/ASQC 9001 on Quality Systems do not define traceability explicitly. ISO 9001 and ANSU/ASQC 9001 instead state the requirements to:

Use measurement equipment in a manner which insures that the measurement uncertainty is known; calibrate measuring equipment against certified equipment having a known valid relationship to internationally or nationally recognized standards; and use ISO 10012, Metrological Confirmation System for Measuring Equipment, for guidance $[\mathrm{C} 4, \mathrm{C} 5]$. 
ISO 10012 The International Organization for Standardization's ISO 10012, Quality Assurance Requirements for Measuring Equipment, refers to the VIM as a normative standard, that is, as a part of itself [C6].

Reasonable Interpretation of the Traceability Required by ISO 9001 ISO 9001 never uses the term traceability with respect to measurement, only product identification, but refers to ISO 10012 in a note for "guidance". ISO 10012 refers to the VIM as a normative reference and, therefore, as a part of itself. Therefore, by reasonable interpretation, if not by the rigorous logic of ISO, an assessor could hold that the traceability required by ISO 9000 is the traceability defined by VIM.

ISO Guide 25 The International Organization for Standardization Guide 25 "Quality Systems for Calibration-Laboratories" incorporates as part of itself the VIM definition of traceability and states that:

Calibration certificates shall, whenever applicable, indicate the traceability to national standards of measurement and shall provide the measurement results and associated uncertainty of measurement and/or a statement of compliance with an identified metrological specification [C7].

ANSI Z540-1 The American National Standard Institute Z540-1, Quality Systems for Calibration Laboratories, definition of and requirement for traceability is virtually the same as ISO Guide 25, but is not word-for-word equivalent. Where ISO Guide 25 says: "traceable to national standards of measurement where available", ANSI Z540-1 says: "traceable to national, international, or intrinsic standards where available" [C8].

NORAMET The North American Metrology Cooperation's definition of traceability is the VIM definition. However, according to the NORAMET interpretation, traceability only exists when metrological evidence is collected to document the traceability chain and its uncertainties; and since uncertainties may have time-dependent components, the evidence must be collected at intervals and the uncertainties re-determined [C9].

\section{References}

C1. International Organization for Standardization, "The International Vocabulary of Basic and General Terms in Metrology", Geneva, Switzerland, 1993.

C2. U.S. Department of Defense, "Military Standard Calibration System Requirements", MilStd-45662A, Washington, DC, August, 1988.

C3. U.S. Department of Defense, Notice of Cancellation: Mil-Std-45662A, Washington, DC, Feb. 27, 1995. 
C4. International Organization for Standardization, "Quality Systems", ISO 9001, Geneva Switzerland, 1994.

C5. American National Standards Institute and American Society of Quality Control, "Quality Systems", ANSI/ASQC Q9001-1994, New York, New York, 1994.

C6. International Organization for Standardization, "Quality Assurance Requirements for Measuring Equipment, ISO 10012-1:1992(E), Geneva, Switzerland, 1992.

C7. International Organization for Standardization, "General Requirements for the Competence of Calibration and Testing Laboratories", ISO/IEC Guide 25 1990(E), Geneva, Switzerland, 1990.

C8. American National Standard Institute, "Calibration Laboratories and Measuring and Test Equipment - General Requirements", ANSINCSL Z540-1-1994, New York, New York, 1994.

C9. North American Metrology Cooperation, "Traceability", NORAMET Document No. 7 (1997-04-23), National Institute of Standards and Technology, Gaithersburg, Maryland, 1997. 


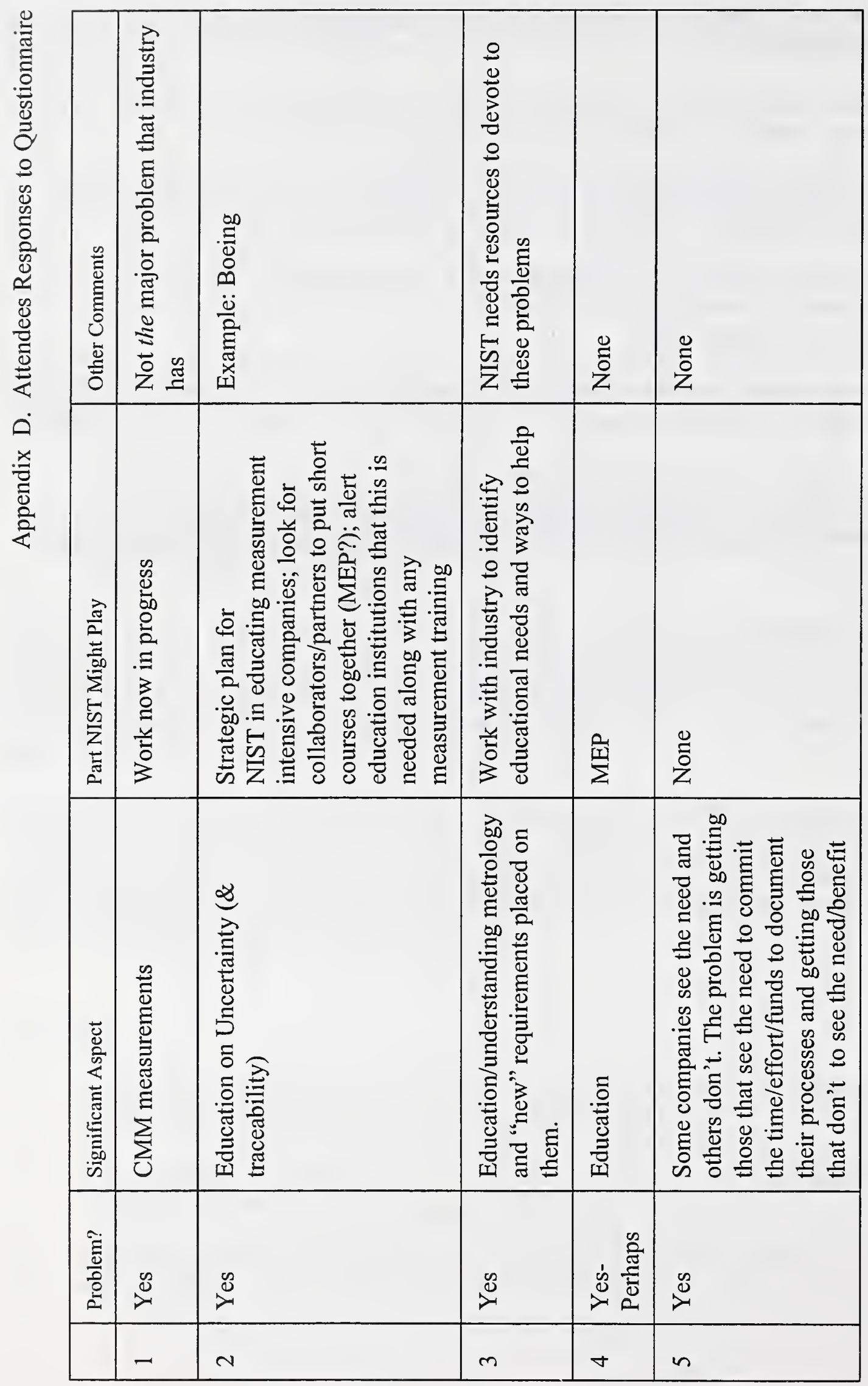




\begin{tabular}{|c|c|c|c|c|c|}
\hline ஜ̃ & 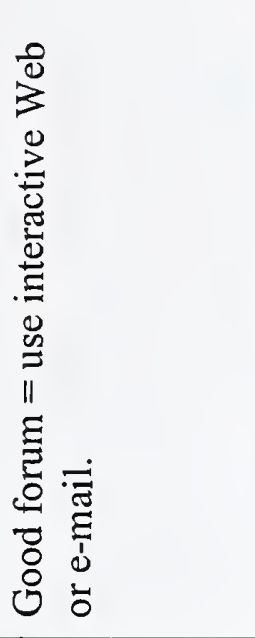 & $\stackrel{0}{Z}$ & 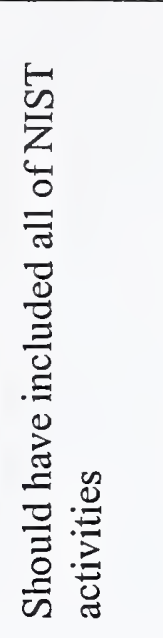 & 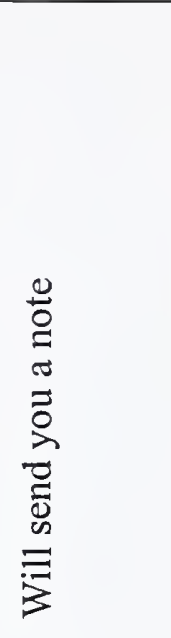 & 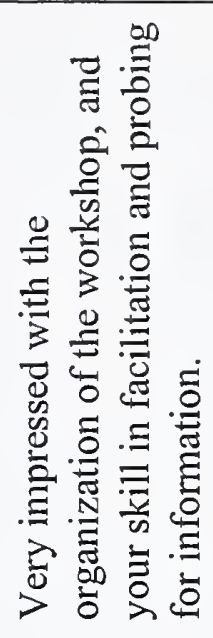 \\
\hline 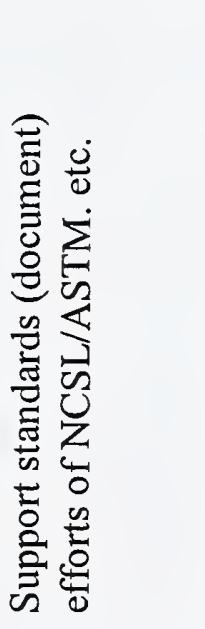 & 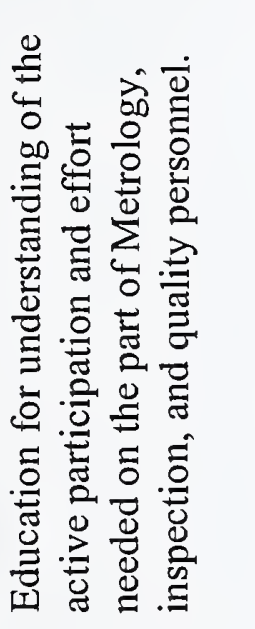 & 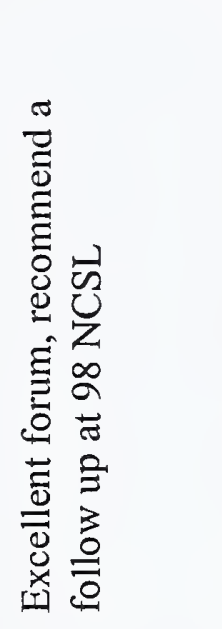 & 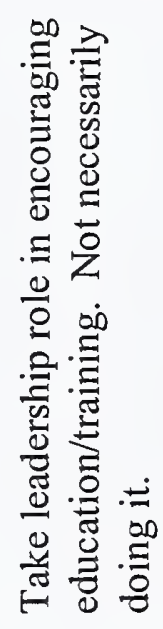 & $\stackrel{0}{0}$ & 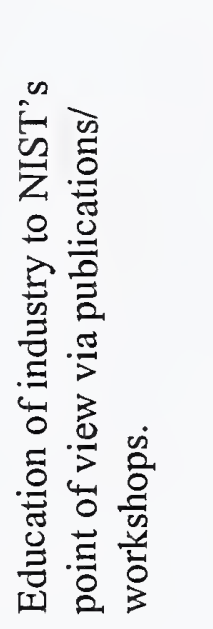 \\
\hline 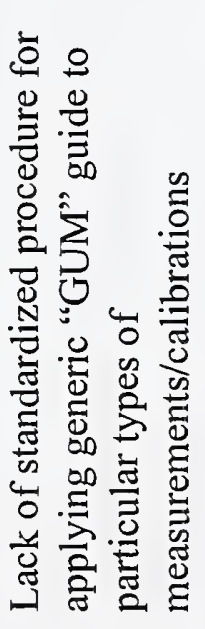 & 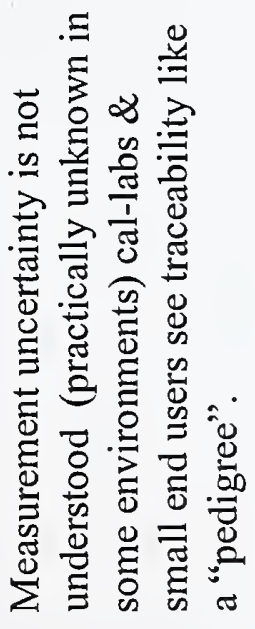 & 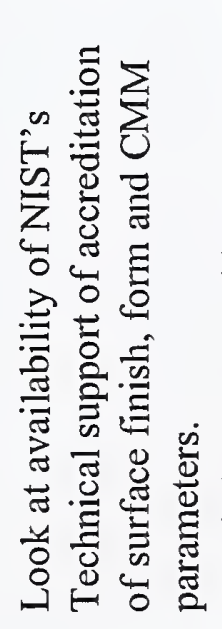 & 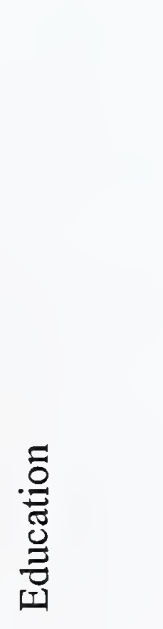 & 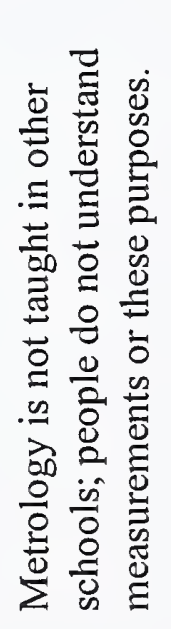 & 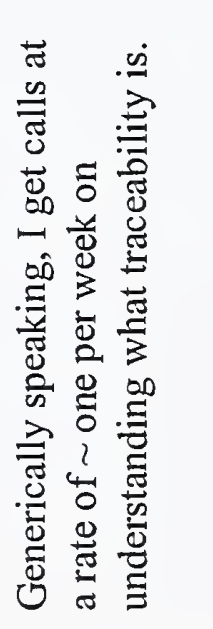 \\
\hline$\stackrel{\infty}{\nu}$ & $D_{\nu}^{00}$ & $\stackrel{\infty}{\circlearrowright}$ & $\stackrel{0}{\infty}$ & $\stackrel{\infty}{\infty}$ & $\stackrel{\infty}{\infty}$ \\
\hline 6 & $r$ & $\infty$ & $a$ & 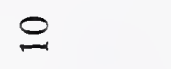 & $=$ \\
\hline
\end{tabular}




\begin{tabular}{|c|c|c|c|}
\hline 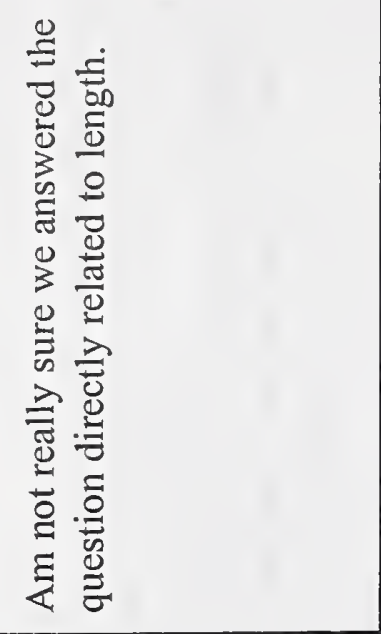 & $\stackrel{\circ}{0}$ & 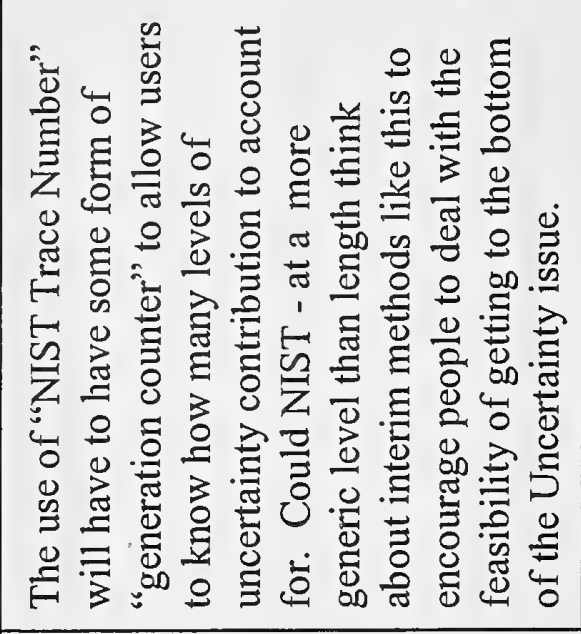 & 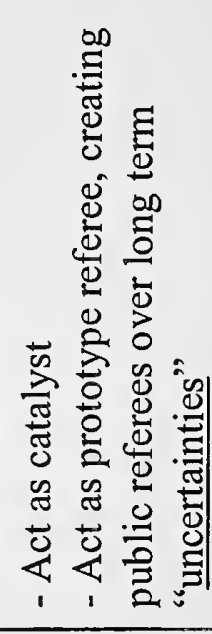 \\
\hline 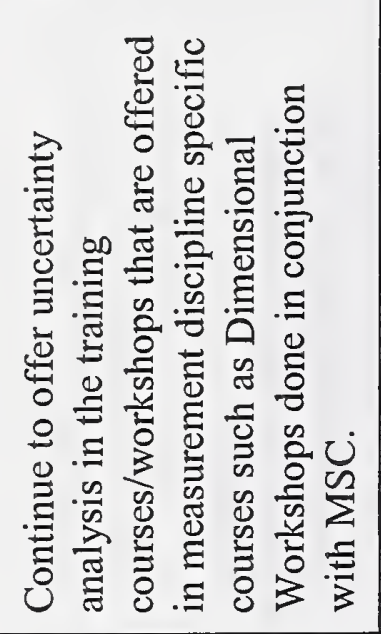 & 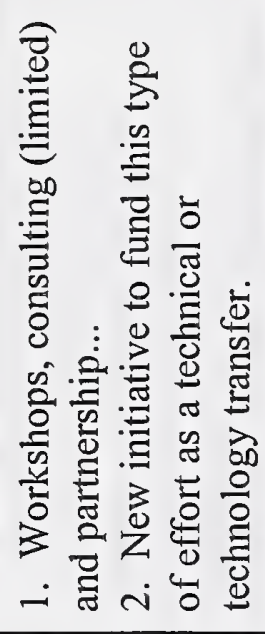 & 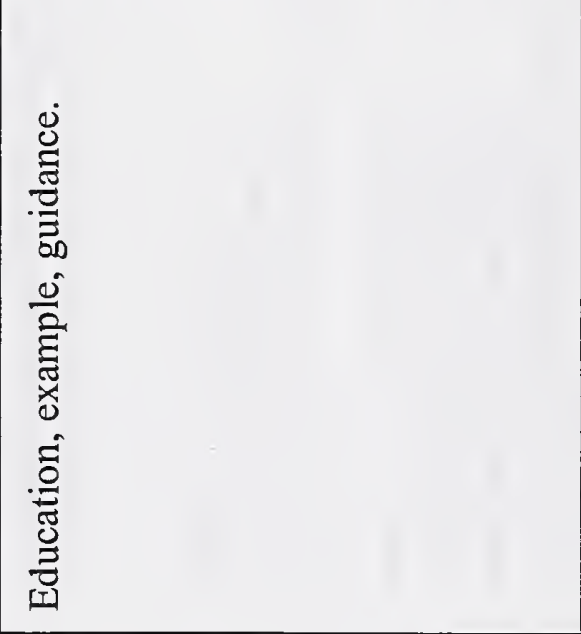 & 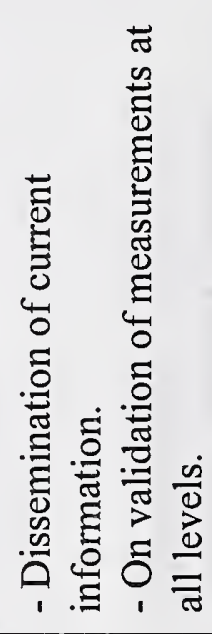 \\
\hline 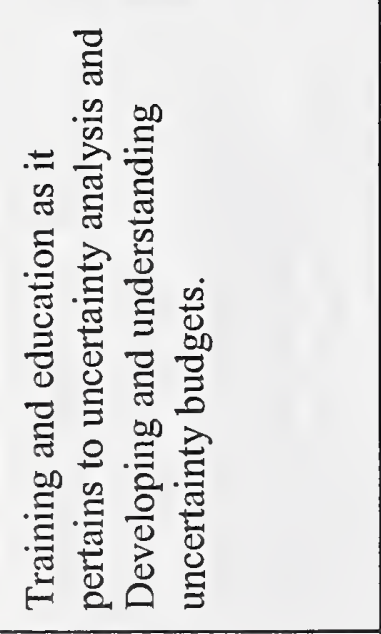 & 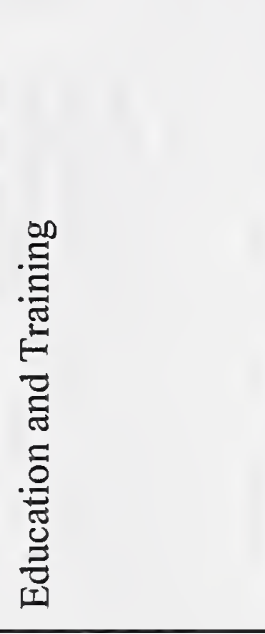 & 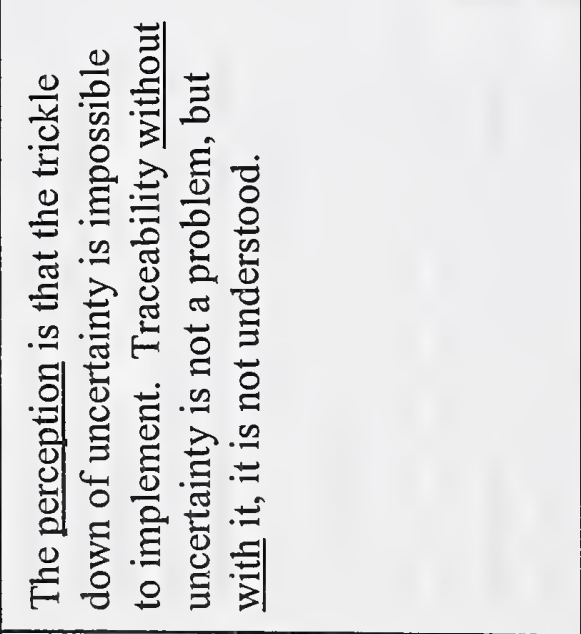 & 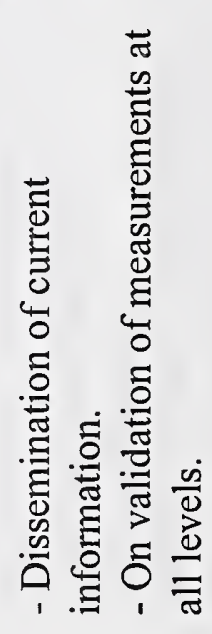 \\
\hline$y^{\infty}$ & 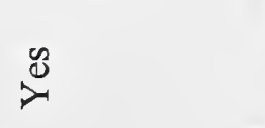 & $\stackrel{\circ}{z}$ & $\overbrace{\nu}^{\infty}$ \\
\hline$\simeq$ & $\underline{M}$ & \pm & $\cong$ \\
\hline
\end{tabular}



